\title{
Unusual fatigue behavior of friction-stir welded Al-Mg-Si alloy
}

Igor Vysotskiy ${ }^{1}$, Sergey Malopheyev ${ }^{1}$, Salaheddin Rahimi², Sergey Mironov ${ }^{1^{*}}$, Rustam Kaibyshev ${ }^{1}$

${ }^{1}$ Laboratory of Mechanical Properties of Nanostructural Materials and Superalloys, Belgorod National Research University, Pobeda 85, Belgorod 308015, Russia

${ }^{2}$ Advanced Forming Research Centre (AFRC), University of Strathclyde, 85 Inchinnan Drive, Inchinnan, Renfrew, PA4 9LJ, United Kingdom

In this work, high-cycle fatigue behavior of friction-stir welded AA6061-T6 was studied. An emphasis has been made on the inter-relationship between microstructure, residual stress and fatigue resistance. The welds were produced under optimized conditions, including a combination of relatively high welding temperature and rapid cooling rate, and subsequently undergone a standard post-weld aging heat treatment. The optimized welds exhibited excellent fatigue performance that was comparable (or even superior) to that of the base material. This result was attributed to a considerable grain refinement in the stir zone, subtle material softening in the heat-affected zone as well as to significant residual stress generated during the optimized FSW.

Keywords: Heat treatable aluminum alloys; Friction-stir welding; Fatigue; Microstructure; Residual stress

\section{Introduction}

Heat treatable aluminum alloys are widely used in transportation and automotive industries owing to their optimal combination of low density, good service characteristics and reasonably low cost. However, the weldability of this grade of materials using conventional fusion welding is rather poor. This drawback necessitates a need for an alternative joining approach, such as bolts and rivets for manufacturing of large structures, thus increasing total weight and cost, with deteriorated structural integrity. In this regard, friction-stir welding (FSW), an innovative solid-state welding technology [1, 2], is often considered as a promising technique for joining these alloys. Taking into consideration the exposure of most parts and structures to cyclic loading in transportation sector, understanding the fatigue behavior of friction-stir welded heat-treatable aluminum alloys becomes imperative [3-30].

An extensive body of research on this subject over the past two decades has shown that fatigue properties of friction-stir joints exceeded those of the fusion welds [1-5]. On the other hand, fatigue performance of friction-stir weldments is typically lower than that of the base material $[1,2,6,7]$.

It is known that fatigue crack is often, though not always, initiated from imperfections of material surface. In this context, the characteristic tool marks, normally generated during FSW on the upper weld surface, are of a great concern. The relatively sharp profile of such marks may result in stress concentration that becomes favorable sites for fatigue crack initiation and thereby highly detrimental for fatigue performance [1, 2]. Accordingly, an elimination of the tool marks by machining is often found to be beneficial for improving resistance to fatigue $[1,2,8]$. 
In the machined welds, for which the surface finish is not an important issue, three factors are believed to play a dominant role on the fatigue life; these include (i) welding defects, (ii) residual stress, and (iii) microstructure [1, 2]. Therefore, without a detailed consideration of all these three factors and their interactions, it is hard to draw a conclusion on the fatigue behavior. This is believed to explain the contradictory nature of the results reported in literature on FSW [2].

Despite welding defects being generally deteriorating for fatigue resistance, it has been shown that defects of up to a certain size ( 10 pct. of the sample thickness) are tolerable without compromising fatigue performance significantly, compared to defect-free joints [9]. On the other hand, due to of the nature of the FSW process, the produced welds typically contain "kissing bond" (or "hook") defects [31]. This inherent attribute of the friction-stir joint may serve as a precursor for a fatigue crack [10, 11]. This issue should be taken into account when considering even nominally defect-free welds.

Since FSW gives rise to a localized heating and thermal expansion and contraction between the hot stirred material and the cold base material, the produced welds are normally associated with thermally induced residual stresses that may substantially affect the fatigue behaviors [1, 2, 12-18]. Specifically, the crack nucleation and propagation are well known to be promoted by tensile residual stress, whereas the compressive residual stress may result in crack retardation. Often, the introduction of compressive residual stress in FSW joints, using shot peening or low-plasticity burnishing, are recommended to enhance fatigue performance. These treatments generate significant level of compressive stress in near-surface layer and thus essentially improve fatigue endurance [14, 15, 17]. On the other hand, the stress-relief heat treatment has been reported to deteriorate fatigue strength [2].

Considering the microstructural factor affecting the fatigue strength, previous studies demonstrated clearly that FSW of heat treatable aluminum alloys normally leads to the dissolution and/or coarsening of the constituent strengthening precipitates, which results in material softening [1, 2, 32-34]. The precipitate growth occurring in the heat-affected zone is believed to be a particularly undesirable effect, since post-weld aging cannot recover material strength [34-38]. Accordingly, the friction-stir welds exhibit relatively low joint efficiency under both static and cyclic loading by typically failing from the heat-affected zone [37, 38].

In a previous study [39], a simple but effective approach has been proposed to improve strength in friction-stir welded heat treatable aluminum alloys. This involved FSW at a combination of relatively high spindle- and feed rates followed by a standard post-weld aging. The selected combination of welding variables provided high welding temperature as well as rapid cooling rate. This led to a complete dissolution of strengthening precipitates in the stir zone, though hindered the coarsening of precipitates in the heat-affected zone. Accordingly, the post-weld aging resulted in an almost homogeneous precipitation of the strengthening dispersoids throughout the weld zone and thus essentially narrowed the softened region. 
It has been shown that the above approach promoted excellent strength characteristics under static loading; specifically, the joint yield strength has been found to be around 90 pct. [39]. On the other hand, the feasibility of the above approach for improving fatigue performance has not been examined, and hence one of the main objectives of the present work. Accounting for a stochastic character of fatigue crack nucleation, it could be suggested that the substantial narrowing of the softened zone in the optimized welds may give rise to a nearly 100-pct. joint efficiency for the fatigue strength.

\section{Experimental Procedures}

\subsection{Material and processing}

The material used in this study was a commercial AA6061 aluminum alloy with a measured chemical composition (in wt. pct.) of $0.88 \mathrm{Mg}, 0.66 \mathrm{Si}, 0.72 \mathrm{Fe}, 0.26 \mathrm{Cu}, 0.12 \mathrm{Mn}, 0.12 \mathrm{Cr}, 0.09 \mathrm{Zn}$, and balance Al. This is a typical heat-treatable aluminum alloy which has been used in a previous work for the examination of static mechanical behavior of the optimized friction-stir welds [39]. The material was produced by semi-continuous casting followed by homogenization at $380^{\circ} \mathrm{C}(653 \mathrm{~K})$ and a subsequent extrusion at the same temperature to $\sim 75$ pct. of area reduction. From the extruded billets, sheets with 3-mm-thickness were machined and then subjected to T6 tempering, i.e. solution annealing at $550^{\circ} \mathrm{C}$ $(823 \mathrm{~K})$ for 1 hour, water quenching and subsequent artificial aging at $160^{\circ} \mathrm{C}(433 \mathrm{~K})$ for 8 hours.

The tempered material was friction-stir butt welded using an AccurStir 1004 FSW machine. The welding tool consisted of a shoulder with $12.5 \mathrm{~mm}$ diameter and an M5 cylindrical probe of $1.9 \mathrm{~mm}$ in length. To avoid a formation of the "kissing bond" defect, a double-sided FSW was applied in the same welding direction. To maintain a consistency with the previous work [39], the optimized welding conditions, i.e. the spindle rate of $1100 \mathrm{rpm}$, the feed rate of $760 \mathrm{~mm} / \mathrm{min}$ and a tilting angle of $2.5^{\circ}$, were implemented. The principal directions of the FSW geometry were denoted throughout as the welding direction (WD), transverse direction (TD) and normal direction (ND).

To retain mechanical properties following FSW, the welds were artificially aged at $160^{\circ} \mathrm{C}(433 \mathrm{~K})$ for 8 hours $^{\dagger}$. Taking into an account the initial T6 heat treatment and the post-weld heat-treatment, the parent material was subjected to 16 hours of artificial aging. This was referred as the base material throughout the manuscript ${ }^{\ddagger}$.

To minimize the possibility of natural aging of the material and hence its potential effect on mechanical properties, the post-weld heat treatment was performed within $\sim 20$ min of the FSW process. Note that all microstructural observations and examinations of mechanical properties in this work were conducted on the post-weld heat-treated samples, i.e. as-welded material condition was not examined.

${ }^{\dagger}$ Note: The-post weld aging was performed following the same procedure as that used for the aging during the initial T6 tempering.

¥Note: Fatigue behavior of the parent material subjected to the standard T6 tempering (including 8-hours aging at $160^{\circ} \mathrm{C}$ ) was not studied in the present work. 


\subsection{Microstructure characterizations}

Microstructural observations were carried out with the aid of optical microscopy, electron backscatter diffraction (EBSD) and transmission electron microscopy (TEM) techniques. For optical microscopy examinations, the specimens were prepared a mirror finished condition, using conventional polishing methods, and chemically etched in Keller's reagent.

A suitable surface finish for EBSD and TEM were obtained using electro-polishing in a solution of 25 pct. nitric acid in methanol solution. EBSD acquisition was carried out using a fully automated TSL $\mathrm{OIM}^{\mathrm{TM}}$ system interfaced to a FEI Quanta 600 field-emission-gun scanning electron microscope (FEG SEM), with an accelerating voltage of $20 \mathrm{kV}$. TEM study was performed using a JEM-2100EX TEM operating at $200 \mathrm{kV}$.

Further details on microstructural examinations of the same material and the weld were described in a previously reported study [39].

\subsection{Residual stress measurements}

Residual stress components, both along the TD and the ND, were measured on the weld crosssection, by x-ray diffraction (XRD) technique using a PROTO-LXRD diffractometer and the $\sin ^{2} \psi$ method [40]. The measurements were carried out on an electro-polished sample, to avoid undesired stress generated during grinding and polishing stages of the sample preparation. The same procedure as that used for the EBSD sample preparation was employed for electro-polishing. A cobalt target and accelerated voltage of $25 \mathrm{kV}$ were used to produce $\mathrm{X}$-ray beam with a wavelength of 1.79026 angstrom. A round collimator with $1 \mathrm{~mm}$ radius and eleven $\psi$-off set angles in the range of maximum $\pm 33^{\circ}$ were employed. The stresses were calculated from the strains of the $\{311\}$ Bragg reflection at $148.9^{\circ}$ Bragg angle, assuming X-ray elastic constants of $S_{1}^{(h k l)}=4.58 \times 10^{-6} \mathrm{MPa}^{-1}$ and $1 / 2 S_{2}^{(h k l)}$ $=18.45 \times 10^{-6} \mathrm{MPa}^{-1}$. To examine the distribution of the residual stresses on the weld cross-section, the measurements were performed on a rectangular grid at equally spaced points, $1 \mathrm{~mm}$ distance in both ND and TD, encompassing the entire double-sided weld and the base material on both advancing side and retreating side of the weld. For each point in both directions 10 measurements with $1 \mathrm{~s}$ exposure time for each measurement were performed.

\subsection{Fatigue performance}

To evaluate fatigue performance of the welded material, dog-bone-shaped specimens were machined with their lengths perpendicular to the WD. The specimens were centered along the weld line, had a gage section of $30 \mathrm{~mm}$ in length and $8 \mathrm{~mm}$ in width, and included all characteristic FSW zones. To achieve a uniform thickness and to prevent potential effect of surface defects on the fatigue life, both surfaces of the specimens were mechanically polished to a final 2400 grit size SiC emery paper. Accordingly, the final thickness of the polished specimens varied between $1.5 \mathrm{~mm}$ to $2.5 \mathrm{~mm}$. Note that the lateral surface of the specimens was produced by electrical-discharge machining (EDM) 
and thereby had a recast layer with a relatively high roughness. Further details of the specimens design are given in supplementary Fig. S1. For the aid of comparison, sufficient specimens were also machined from the base material, using the same surface preparation procedure. The fatigue tests were conducted using an Instron 8801 servo-hydraulic testing system in a load control mode and at an ambient temperature. A sinusoidal load-time function with a frequency of $50 \mathrm{~Hz}$ and a maximum-tominimum load ratio of $R=0.1$ was used. Despite the temperature was not controlled throughout the test, the samples were found to be cold to the touch at the end of the tests; therefore, a strain-induced heating can be considered as very small. All information on the fatigue tests were summarized in Table 1. Statistical analysis of the test results was carried out in accordance with ASTM E 739-91 standard. Fracture surface of the failed specimens was examined with FEI Quanta 600 FEG-SEM.

\subsection{Static mechanical behavior}

For the aid of comparison, static transverse tensile tests as well as microhardness measurements were conducted. Vickers microhardness measurements were carried out by applying $200 \mathrm{gf}$ with a dwell time of $10 \mathrm{~s}$, using a Woltopert 402 MVD microhardness tester. The tensile tests to failure were performed at an ambient temperature and under a constant cross-head velocity corresponding to a nominal strain rate of $10^{-3} \mathrm{~s}^{-1}$, using an Instron $300 \mathrm{LX}$ universal testing machine. Further details on the experimental procedure of the static mechanical tests can be found elsewhere [39].

\section{Results}

\subsection{Microstructure and static mechanical behavior}

The effect of FSW and subsequent post-weld aging heat-treatment on microstructure and static mechanical behavior of the same grade material has been discussed in details in a previous published work [39]. For convenience, the key results were briefly summarized in this section.

A typical low-magnification macrograph of the weld cross-section is shown in Fig. 1a. A distinct stir zone with a clear overlap between the two FSW passes (i.e., a double-side FSW) can be seen. From this macrograph, it is evident that the weld contained no volumetric flaws including the "kissing bond" defect.

Typical microstructures observed in different microstructural zones of the welds are shown in Figs. 1b-c \& 2. In the base material, the grain structure was dominated by coarse elongated grains representing two textural components, i.e., $<100>/ /$ extrusion direction and $<111>/ /$ extrusion direction (red and blue grains in Fig. 1b, respectively), which presumably originated from the hot extrusion process. The grains contained developed subboundary structure (Fig. 1b) and high density of nanoscale dispersouds evenly distributed in the grain interior (Fig. 2a). As shown in the previous work [39], the precipitates were dominated by the $\beta^{\prime \prime}$ phase which is known to be the main strengthening contributor in the peak-aged 6xxx alloys. 
In the heat-affected zone, no significant change were found neither in grain structure nor in crystallographic texture (not shown) but considerable precipitation coarsening was observed (Fig. 2b). The latter observation was expected and was in agreement with previous reports in scientific literature [e.g. 34-38.]. In the stir zone, the evolved microstructure was dominated by relatively fine grains (Fig. 1c) thus evidencing significant grain refinement occurring during FSW. The post-weld aging heat treatment has resulted in re-precipitation of the $\beta^{\prime /}$ phase (Fig. 2c), but the particles population density was lower than that observed in the base material (compare Figs. 2a \& c).

The static mechanical properties were found to be in a close correlation with the variation in the precipitation distribution. Specifically, the partial particle dissolution and coarsening during FSW resulted in substantial material softening that was most pronounced in the heat-affected zone (Fig. 3a) . $^{\S}$ This led to strain localization in this microstructural region and subsequent premature failure during transverse tensile tests [39]. As a result, the welded material exhibited relatively low strength and ductility (Fig. 3b).

\subsection{Residual stresses}

Considering the significant influence of residual stress on fatigue life, wither beneficial or detrimental, the residual stress distributions were measured on the weld cross-section ${ }^{*}$. Figure $4 a \& b$ show the transverse (along the weld TD) and through-thickness normal (along the weld ND) residual stress maps, respectively. It is clear that the magnitudes and distributions of both residual stress components significantly change with position in the weld. For clarity, the plots of residual stress as a function of distance along three lines across the weld are shown in Fig. $5 a$ \& b for both TD and ND, respectively. These profiles were plotted to illustrate the stress distribution in the center of the stir zones in the second weld pass (line A), that in the first weld pass (line $\mathrm{C}$ ) and also on the interface zone where both weld passes were overlapped (line B), as indicated in Fig. 4.

The uncertainties associated with residual stress measurements were in all cases less than \pm 35 MPa (Fig. 5). Remarkably, the experimental scattering within the stir zone was significantly lower than that measured for the heat-affected zone and the base material (Fig. 5). This was presumably due to substantially finer grain size in the former microstructural region (compare Fig. $1 \mathrm{~b} \& \mathrm{c}$ ) and the respectively-higher sampling statistics.

The residual stress components in both TD and ND are tensile in nature in the weld zone, although some stress free areas can be seen mainly within the first weld pass. Maximum tensile stress of $40 \pm 13$ MPa and 50 $\pm 10 \mathrm{MPa}$ were recorded in the center of the first and the second weld passes, respectively. This shows that the residual stress in the center of the second weld pass is slightly higher than that of the first weld pass. This can be due to the partial stress relaxation that might have occurred in the first

\footnotetext{
$\$$ In Fig. 3a, the heat-affected zone is approximately located between the shoulder diameter and the probe diameter.

${ }^{* *}$ It is known that residual stresses generated during FSW are critically influenced by a clamping fixture of FSW machine [41]. The clamping fixture used in the present work is shown in supplementary Fig. S2.
} 
weld pass while the second weld pass was conducted. Both the transverse and normal residual stress components are very small in the interface zone between the two weld passes, with a maximum of $17 \pm 4 \mathrm{MPa}$ for the former and $4 \pm 3 \mathrm{MPa}$ for the latter.

The transverse residual stress measured for the heat affected zone on advancing side of both weld passes are tensile in nature with a maximum of $\approx 70 \mathrm{MPa}$ for that of the first weld pass (Fig. $4 a$ ). The measured stress in TD for the base material (Fig. 4a) is characteristic of residual stress distribution in an extruded material with a significant compressive stress on both edges counter-balanced by large tensile residual stress in the center. The measured residual stress in ND appears to be tensile in the heat-affected zone and compressive in the base material. From fatigue performance perspective, the stresses in the TD can affect the crack initiation and propagation as this stress component adds up to the applied stress during the fatigue test.

\subsection{Fatigue performance}

The effect of cyclic loading on the fatigue life of the base- and welded material is shown in Fig. 6 a. Details of the fatigue tests are summarized in Table 2. Despite that the results of the fatigue tests were fairly scattered, several important observations can be made.

As may be expected, the fatigue lifetime for both studied material conditions (i.e., the base material and the welded material) was shortened with an increase in the applied stress (Fig. 6a). Also quite expectedly, no clear saturation and thereby a well-defined fatigue limit has been demonstrated by both graphs (Fig. 6a). Therefore, a fatigue limit strength corresponding to $10^{7}$ cycles was accepted as a measure of high-cycle fatigue performance for this work. In compliance with the ASTM E 1823-96 standard, the fatigue limit strength is the maximal stress amplitude for which at least 50 pct. of the tested specimens are survived after a predetermined number of cycles. On this basis, the fatigue limit strength for the base material was determined to be $67.5 \mathrm{MPa}$, whereas that for the welded material was 76.5 MPa (Table 2). This shows that the friction-stir welded microstructure exhibited superior fatigue limit strength compared to the base material.

To further evaluate this outcome, the obtained fatigue data were statistically analyzed in accordance with the recommendations in ASTM E 739-91 standard. For this purpose, the data for the samples that did not fail during the test (and identified as the run-out tests in Fig. 6a) as well as suspicious data were all excluded from the analysis ${ }^{\dagger \dagger}$. The remaining data were shown in Fig. $6 \mathrm{~b}$ with a linear fitting. It is clear from this figure that the fatigue strength of the welded material, at relatively low stress amplitudes, had indeed exceeded that of the base material. At relatively high cyclic stresses however, the measured data for both material conditions tended to overlap, thus perhaps indicating a comparable strength.

Another important point was the location of failure in the welded specimens. At relatively low stress amplitudes (i.e., below <94.5 MPa), the welded specimens failed typically in the base material section

ttThe data excluded from consideration consisted of 13 run-out tests, including 2 base material specimens and 11 welded specimens, and 1 suspicious result for the welded material. 
(Table 2) despite the fact that this microstructural region exhibited the highest strength under tensile loading (Fig. 3). At higher stress amplitudes however, the fatigue failure often occurred in the heataffected zone (Table 2), i.e. the softest microstructural region as per the results of microhardness measurements (Fig. 3a).

\subsection{Fracture analysis}

To get additional insight into the fatigue performance of both studied material conditions, the fracture surface of the fatigues specimens was investigated. Three characteristics cases were considered, including (i) the base material, (ii) the weld specimen fatigued at relatively low stress magnitudes where the failures were occurred at the base material section, and (iii) the welds fatigued at relatively high stress magnitudes where the failures were occurred at the heat-affected zone.

Typical appearances of the specimens representing the above three groups were shown in Fig. 7 . The magnified image of failure location was given in the top right corner of each micrograph. For all cases, the fracture surface was complex, comprising of two distinct regions. One of the segments was relatively flat thus presumably indicating a brittle mechanism of fracture. Another one was characterized by a developed surface relief thus probably evidencing a ductile failure (high magnification inserts in Fig. 7) ${ }^{\ddagger \ddagger}$.

Direct observations of fracture surfaces confirmed the complex characteristics of the fatigue failure mechanisms (Figs. 8a, 9a and 10a). In all cases, three characteristic regions were observed which represented three typical stages of fatigue failure, including crack initiation (Stage I), crack propagation (Stage II), and catastrophic fracture (Stage III) [42, 43].

Typically, the fatigue crack was found to initiate at the lateral surface of the specimens, highlighted by arrows on the far left of the micrographs shown in Figs. 8a and 9a. This was likely to be due to a relatively high roughness of these surfaces prior to the commencement of the fatigue tests. In some welded specimens, however, the crack nucleation was observed at the upper surface of the weld (e.g. Figs. 10a \& b); the reason for this effect was unclear, however. The fracture surface caused by Stage I of fatigue failure was highly faceted (Figs. 9b and 10b), thus perhaps indicating that the crack growth occurred by a slip-plane cracking.

The fracture surface caused during Stage II was dominated by fatigue striations and beach marks (Figs. 8c, 9c and 10c) which are conventionally attributed to a discontinuous character of the crack propagation [42]. In some cases, small secondary cracks were also observed (Fig. 8c). Remarkably, the striations were typically arranged into larger-scale banded structure thereby exhibiting a relatively complex character of failure.

\footnotetext{
¥ Note that some fraction of the tested specimens ( 2 out 17 in the base material and 3 out 17 in the welded material) failed either close to the borderline of the gauge section (example is shown in Fig. 7b) or slightly out with the gauge length (example is shown in Fig. 7a). This result was thought to be attributable to a smooth transition between the gauge- and grip sections of the fatigue specimens (supplementary Fig. S1).
} 
The fracture surfaces caused by Stage I and II of the fatigue were relatively smooth thus indicating the brittle characteristic of the failure (Figs. 8b-c, 9b-c and 10b-c). On contrast, fracture surfaces caused by Stage III exhibited dimpled appearances (Figs. 8d, 9d and 10d) indicative of a ductile fracture mechanism governed by the nucleation and coalescence of voids.

Remarkably, the very specific microstructural features resembling Frank-Read dislocation sources were often observed at the bottom surfaces of micro-cracks and dimples (Fig. 11).

Generally, the fracture analysis revealed no principal difference between the specimens studied. This implied a broadly similar crack propagation mechanism in all cases. In this regard, of particular importance was the observation that the overall fracture surface was dominated by the fracture occurred during Stage III (Figs. 8a, 9a and 10a), i.e. the crack propagation resistance was relatively low. It can be suggested therefore that the fatigue performance of the studied materials was dictated by the crack initiation process. However, verification of this idea would require a considerably more detailed study which was out of the scope of the present work.

\section{Discussion}

Having analyzed all important parameters influencing the fatigue performance of friction-stir welded specimens, the following three sections attempt to interpret the observed findings.

\subsection{Overall fatigue behavior}

As mentioned earlier, fatigue behavior of friction-stir welded materials is believed to be governed by (i) geometrical characteristics of FSW process including tool marks and the kissing bond defect, (ii) weld flaws, (iii) microstructure, and (iv) residual stresses [1, 2]. Since the welds examined in the present study contained no volumetric defects (Fig. 1a) and were carefully polished to remove the tool marks (Fig. 7), only the microstructure and the residual stresses can perhaps be the dominant influential factors on the fatigue life.

As suggested above, fatigue life of the examined materials was likely dictated by the crack initiation stage. The fatigue cracks are commonly accepted to nucleate typically from the slip bands [42, 43]. Hence, a suppression of the slip banding due to a grain refinement is often believed to improve the resistance to crack initiation [44-46]. It is likely therefore that the excellent fatigue resistance of the stir zone material revealed in the present work was related (partially, at least) to the pronounced grain refinement occurred in this microstructural region (Fig. 1C). On the other hand, the relatively coarsegrained microstructure in both the base material and the heat-affected zone (Fig. 1b) should promote crack nucleation in these microstructural areas. Moreover, the crack propagation in these regions should be facilitated by the pronounced extrusion texture (Fig. 1b).

The distribution of residual stresses across the weld was fairly heterogeneous thus perhaps indicative of a complex material response to FSW. Previous results reported on double-sided FSW of 
micro-alloyed steel [47] and also dissimilar FSW between duplex steel and carbon steel [48] show a strong correlation between post-weld microstructure and the residual stress distribution. In these studies [47, 48], it was shown that the recrystallized areas of the welds had nearly-zero residual stress in both ND and TD, which was also the case for the measured stresses in the current study (Figs. 4 \& 5). However, the residual stresses are not only influenced by microstructure as the geometrically necessary stresses, caused by differential expansion and contraction between the hot weld and the cold base material during FSW, are generated predominantly at the heat-affected zone. These stresses that are significantly high ( $\sim 50 \mathrm{pct}$. of yield strength) and tensile in nature, combined with relatively large grain size and crystallographic texture at the base material and the heat-affected zone (Fig. 1b), should accelerate the fatigue crack initiation and propagation. In other words, the residual stress at the heat-affected zone should add up to the applied stress during the fatigue tests and thus result in premature failure. In fact, the heterogeneous distribution of the residual stress, particularly the TD component (Fig. 4a), results in non-uniform effective stress (i.e. a sum of applied and residual ones) during the fatigue tests, such that different areas of the specimen will be under different magnitudes of stress.

Therefore, both the residual stress distribution and also the observed microstructural characteristics (i.e., coarse grain size and texture) are favorable for accelerated fatigue fracture at the heat-affected zone, compared to other regions of the weld. Nevertheless, the welds tested at relatively low fatigue stress often failed in the base material region (Fig. 6a and Table 2). To comprehend this result, specific character of fatigue behavior under low- and high cyclic stresses was discussed in the following.

\subsection{Low cyclic stresses}

At relatively low magnitude of cyclic stress $(<210 \mathrm{MPa})$, a crack was found to nucleate primarily in the base material zone; however, the welded specimens exhibited generally longer fatigue life than the base-material specimens (Fig. 6a, Table 2).

This apparently contradictory result could be explained by considering two factors, including (i) the stochastic nature of fatigue crack nucleation, and (ii) compressive character residual stresses in the near-surface layer of the base material region (Fig. 4). Indeed, the fatigue stress in this case did not exceed $\sim 60-70$ pct. of static yield strength (Table 2 ) and therefore initiation of the fatigue crack was probably governed by purely stochastic factors. Since the base material section comprised $\sim 60$ pct. of the gauge length of fatigue specimens, statistical probability of the crack nucleation in this microstructural region was greatest. It was also highly likely the initiation of the fatigue crack was additionally promoted by the coarse-grained microstructure as well as the pronounced crystallographic texture in the base material zone (Fig. 1b).

On the other hand, due to the relatively high residual compressive stress generated during FSW (Figs. 4 \& 5), the base material zone of the welded specimens should exhibit higher fatigue resistance than the original material. 


\subsection{High cyclic stresses}

As relatively high magnitudes of cyclic stress $(\geq 210 \mathrm{MPa})$, the weldments often failed in the heataffected zone (Fig. 6a, Table 2), i.e. the softest microstructural region. Nevertheless, the welded specimens showed the fatigue strength comparable to that of the base material specimens (Fig. 6a).

To comprehend fatigue behavior in this case, it is important to realize that the maximal cyclic stresses reached $\sim 90$ pct. of the static yield strength (Table 2). Considering a relatively high residual tensile stress on advancing side of the heat-affected zone (Fig. 4a), it is likely that the effective stress in this area exceeded the yield strength level and thus the material experienced a plastic strain prior nucleation of the fatigue crack.

To evaluate this idea, microhardness profiles were measured across the failed welds and compared with these of the non-fatigued ones, as exemplified in Fig. 12. The measurable material strengthening revealed in the softened zone after fatigue test can be an indicative of a strain hardening effect. If so, the fatigue crack indeed originated from a preceding plastic strain. This perhaps explains the observed failure of the weldments in the softest microstructural region (i.e., the heat-affected zone). On the other hand, due to a relatively small difference in strength between this microstructural region and the base material ( 10 pct., as follows from Fig. $3 a$ ) as well as a substantial influence of the stochastic factor on the cyclic behavior, the fatigue strength of the welded specimens was comparable to that of the base material and a significant portion of the welds failed in the parent material zone.

With approaching of the level cyclic stresses to the yield strength, the role of the plastic strain on the fatigue performance should increase. This is consistent with fatigue diagrams in Fig. $6 \mathrm{~b}$ which $\mathrm{h}$ predicts inferior fatigue strength of the welded material in the low-cycle fatigue range.

\section{Conclusions}

In this work, high-cycle fatigue behavior of friction-stir welded AA6061-T6 was studied. The welds were produced under an optimized condition which involved FSW at a combination of relatively high welding temperature and rapid cooling rate followed by a standard post-weld aging. The optimized treatment resulted in relatively narrow heat-affected zone. Fatigue test were performed at ambient temperature, under a load ratio of $R=0.1$ and a range of maximal stresses from $150 \mathrm{MPa}$ to $240 \mathrm{MPa}$. Statistical analysis of the test results was carried out in accordance with ASTM E 739-91 standard. The main findings of this work were concluded as follows.

1) The optimized welds exhibited excellent fatigue performance that was comparable (or even superior) to that of the base material.

2) At relatively low fatigue stress ( $<210 \mathrm{MPa})$, the welds typically failed in the base material zone. This effect was attributed to a combination of relatively narrow softened region in the welded material 
and stochastic nature of the fatigue crack nucleation at low cyclic stress. Remarkably, the welded specimens showed longer fatigue life than the base-material specimens. This observation was explained in terms of relatively-high compressive residual stress (up to $\sim 80 \mathrm{MPa}$ ) generated in the base-material region during FSW.

3) At relatively high fatigue stress ( $\geq 210 \mathrm{MPa}$ ), fracture often occurred in the softest microstructural region, i.e. the heat-affected zone. This result was associated with substantial residual tensile stress (up to $\sim 70 \mathrm{MPa}$ ) produced in this area during FSW. It was suggested that a sum of the fatigue stress and the residual stress in this zone exceeded the yield point and therefore the material experienced a plastic strain prior to the nucleation of fatigue crack. On the other hand, due to subtle character of softening effect in the heat-affected zone and the stochastic nature of the fatigue cracking, significant portion of the welds failed in the base material region and fatigue strength of the welded specimens was comparable to that of the parent material.

4) In all cases, fatigue cracking was facilitated by relatively coarse-grained microstructure and pronounced crystallographic texture inherent to the base material and the heat-affected zone.

5) Despite the significant tensile residual stress revealed in the stir zone (up to $~ 50 \mathrm{MPa}$ ), none of the welds failed in this microstructural region. This result was attributed to significant grain refinement occurred in this area during FSW.

\section{Acknowledgments}

This work was financially supported by the Russian Science Foundation, grant No. 18-79-10174. The authors are grateful to the staff of the Joint Research Center «Technology and Materials» at Belgorod State National Research University for their assistance with experimental work.

\section{Data availability}

The raw/processed data required to reproduce these findings cannot be shared at this time as the data also forms part of an ongoing study.

Declarations of interest: none

\section{References}

[1] R.S. Mishra, Z.Y. Ma, Friction stir welding and processing, Mater. Sci. Eng. R 50 (2005) 1-78; https://doi.org/10.1016/j.mser.2005.07.001

[2] P.L. Threadgill, A.J. Leonard, H.R. Shercliff and P.J. Withers, Friction stir welding of aluminum alloys, Int. Mater. Rev. 54 (2009) 49-93; https://doi.org/10.1179/174328009X411136

[3] M. Ericsson, R. Sandstrom, Influence of welding speed on the fatigue of friction stir welds, and comparison with MIG and TIG, Int. J. Fatigue 25 (2003) 1379-1387; https://doi.org/10.1016/S01421123(03)00059-8 
[4] P.M.G.P. Moreira, M.A.V. de Figueiredo, P.M.S.T. de Castro, Fatigue behavior of FSW and MIG weldments for two aluminum alloys, Theor. Appl. Fract. Mechan. 48 (2007) 169-177; https://doi.org/10.1016/j.tafmec.2007.06.001

[5] D. Texier, F. Atmani, P. Bocher, F. Nadeau, J. Chen, Y. Zedan, N. Vanderesse, V. Demers, Fatigue performance of FSW and GMAW aluminum alloys welded joints: competition between microstructural and structural-contact-fretting crack initiation, Int. J. Fatigue 116 (2018) 220-233; https://doi.org/10.1016/j.ijfatigue.2018.06.020

[6] Y. Uematsu, K. Tokaji, H. Shibata, Y. Tozaki, T. Ohmune, Fatigue behavior of friction stir welds without neither welding flash nor flaw in several aluminum alloys, Int. J. Fatigue 31 (2009) 1443-1453; https://doi.org/10.1016/j.ijfatigue.2009.06.015

[7] S.S. Di, X.Q. Yang, G.H. Luan and B. Jian, Comparative study on fatigue properties between AA2024-T4 friction stir welds and base materials, Mater. Sci. Eng. A 435 (2006) 389-395; https://doi.org/10.1016/j.msea.2006.07.009

[8] S. Lomolino, R. Tovo, J. Dos Santos, On fatigue behavior and design curves of friction stir buttwelded Al alloys, Int. J. Fatigue 27 (2005) 305-316; https://doi.org/10.1016/j.ijfatigue.2004.06.013

[9] T.L. Dickerson, J. Przydatek, Fatigue of friction stir welds in aluminum alloys that contain root flaws, Int. J. Fatigue 25 (2003) 1399-1409; https://doi.org/10.1016/S0142-1123(03)00060-4

[10] A. Oosterkamp, L.D. Oosterkamp, A. Nordeide, "Kissing bond" phenomena in solid-state welds of aluminum alloys, Welding J. 83 (2004) 225-S

[11] C. Zhou, X. Yang, G. Luan, Effect of root flaws on the fatigue property of friction stir welds in 2024T3 aluminum alloys, Mater. Sci. Eng. A. 418 (2006) 155-160. https://doi:10.1016/j.msea.2005.11.042.

[12] G. Bussu, P.E. Irving, The role of residual stress and heat affected zone properties on fatigue crack propagation in friction stir welded 2024-T351 aluminum joints, Int. J. Fatigue 25 (2002) 77-88; https://doi.org/10.1016/S0142-1123(02)00038-5

[13] R. John, K.V. Jata, K. Sadananda, Residual stress effects on near-threshold fatigue crack growth in friction stir welds in aerospace alloys, Int. J. Fatigue 25 (2003) 939-948; https://doi.org/10.1016/j.ijfatigue.2003.08.002

[14] O. Hatamleh, J. Lyons, R. Forman, Laser and shot peening effects on fatigue crack growth in friction stir welded 7075-T7351 aluminum alloy joints, Int. J. Fatigue 29 (2007) 421-434; https://doi.org/10.1016/j.ijfatigue.2006.05.007

[15] O. Hatamleh, A comprehensive investigation on the effect of laser and shot peening on fatigue crack growth in friction stir welded AA 2195 joints, Int. J. Fatigue 31 (2009) 974-988; https://doi.org/10.1016/j.ijfatigue.2008.03.029

[16] L. Fratini, S. Pasta, A.P. Reynolds, Fatigue crack growth in 2024-T351 friction stir welded joints: longitudinal residual stress and microstructural effects 31 (2009) 495-500; https://doi.org/10.1016/j.ijfatigue.2008.05.004

[17] S. Hassanifard, H. Mousavi, A. Varvani-Farahani, The influence of low-plasticity burnishing process on the fatigue life of friction-stir-processed Al 7075-T6 samples, Fatigue Fract. Eng. Mater. Structur. 42 (2019) 764-772; https://doi.org/10.1111/ffe.12950

[18] W.Y. Li, N. Li, X.W. Yang, Y. Feng, A. Vairis, Impact of cold spraying on microstructure and mechanical properties of optimized friction stir welded AA2024-T3 joint, Mater. Sci. Eng. A 702 (2017) 73-80; https://doi.org/10.1016/j.msea.2017.07.003

[19] K.V. Jata, K.K. Sankaran, J.J. Ruschau, Friction-stir welding on microstructure and fatigue of aluminum alloy 7050-T7451, Metall. Mater. Trans. A 31 (2000) 2181-2192, https://doi.org/10.1007/s11661-000-0136-9 
[20] D.M. Rodrigues, A. Loureiro, C. Leitao, R.M. Leal, B.M. Chaparro, P. Vilaca, Influence of friction stir welding parameters on the microstructural and mechanical properties of AA6016-T4 thin welds, Mater. Design 30 (2009) 1913-1921; https://doi.org/10.1016/j.matdes.2008.09.016

[21] P. Cavaliere, M. Cabibbo, F. Panella, A. Squillace, 2098 Al-Li plates joined by friction stir welding: mechanical and microstructural behavior, Mater. Design 30 (2009) 3622-3631; https://doi.org/10.1016/j.matdes.2009.02.021

[22] P. Cavaliere, E. Cerri, A. Squillace, Mechanical response of 2024-7075 aluminum alloys joined by friction stir welding, J. Mater. Sci. 40 (2005) 3669-3676; https://doi.org/10.1007/s10853-005-0474-5

[23] G. Sun, C. Wang, X. Wei, D. Shang, S. Chen, Study on small fatigue crack initiation and growth for friction stir welded joints, Mater. Sci. Eng. A 739 (2019) 71-85; https://doi.org/10.1016/j.msea.2018.10.002

[24] E. Maggiolini, D. Benasciutti, L. Susmel, D.G. Hattingh, M.N. James, R. Tovo, Friction stir welds in aluminum: design S-N curves from statistical analysis of literature data, Fatigue Frac. Eng. Mater. Structur. 41 (2018) 2212-2230; https://doi.org/10.1111/ffe.12805

[25] S. Kim, C.G. Lee and S.-J. Kim, Fatigue crack propagation behavior of friction stir welded 5083H32 and 6061-T651 aluminum alloys, Mater. Sci. Eng. A 478 (2008) 56-64; https://doi.org/10.1016/j.msea.2007.06.008

[26] P. Cavalire, G. Campanile, F. Panella and A. Squillace, Effect of welding parameters on mechanical and microstructural properties of AA6056 joints produced by friction stir welding, J. Mater. Process. Technol. 180 (2006) 263-270; https://doi.org/10.1016/j.jmatprotec.2006.06.015

[27] K.V. Jata, K.K. Sankaran and J.J. Ruschau, Friction-stir welding effects on microstructure and fatigue of aluminum alloy 7050-T7451, Metall. Mater. Trans. A 31 (2000) 2181-2192; https://doi.org/10.1007/s11661-000-0136-9

[28] C. He, Y. Liu, J. Dong, Q. Wang, D. Wagner, C. Bathias, Through thickness property variations in friction stir welded AA6061 joint fatigued in very high cyclic fatigue regime, Int. J. Fatigue, 82 (2016) 379-386; https://doi.org/10.1016/j.ijfatigue.2015.08.013

[29] C. Deng, R. Gao, B. Gong, T. Yin, Y. Liu, Correlation between micro-mechanical property and very high cycle fatigue (VHCF) crack initiation in friction stir welds of 7050 aluminum alloy, Int. J. Fatigue 104 (2017) 283-292; https://doi.org/10.1016/j.ijfatigue.2017.07.028

[30] P.S. Effertz, V. Infante, L. Quintino, U. Suhuddin, S. Hanke, J.F. dos Santos, Fatigue life assessment of friction spot welded 7050-T76 aluminum alloy using Weibull distribution, Int. J. Fatigue 87 (2016) 381-390; https://doi.org/10.1016/j.ijfatigue.2016.02.030

[31] Y.S. Sato, H. Takauchi, S.H.C. Park, H. Kokawa, Characteristics of the kissing-bond in friction stir welded Al alloy 1050, Mater. Sci. Eng. A 405 (2005) 333-338; https://doi.org/10.1016/j.msea.2005.06.008

[32] G. Liu, L.M. Murr, C.S. Niou, J. C. McClure, F.R. Vega, Microstructural aspects of the friction-stir welding of 6061-T6 aluminum, Scripta Mater. 37 (1997) 355-361; https://doi.org/10.1016/S13596462(97)00093-6

[33] Y.S. Sato, H. Kokawa, M. Enomoto, S. Jogan, Microstructural evolution of 6063 aluminum during friction-stir welding, Metall. Mater. Trans. A 30 (1999) 2429-2437; https://doi.org/10.1007/s11661-9990251-1

[34] Y.S. Sato, H. Kokawa, M. Enomoto, S. Jogan, T. Hashimoto, Precipitation sequence in friction stir weld of 6063 aluminum during aging, Metall. Mater. Trans. A 30 (1999) 3125-3130; https://doi.org/10.1007/s11661-999-0223-5

[35] W. Woo, H. Choo, D.W. Brown, Z. Feng, Influence of the tool pin and shoulder on microstructure and natural aging kinetics in a friction-stir-processed 6061-T6 aluminum alloy, Metall. Mater. Trans. A 38 (2007) 69-76; https://doi.org/10.1007/s11661-006-9034-0 
[36] W. Woo, H. Choo, P.J. Withers, Z. Feng, Prediction of hardness minimum locations during natural aging in an aluminum alloy 6061-T6 friction stir weld, J. Mater. Sci. 44 (2009) 6302-6309; https://doi.org/10.1007/s10853-009-3868-y

[37] C. Gallais, A. Simar, D. Fabregue, A. Denquin, G. Lapasset, B. de Meester, Y. Brechet, Y. Pardoen, Multiscale analysis of the strength and ductility of AA 6056 aluminum friction stir welds, Metall. Mater. Trans. A 38 (2007) 964-981; https://doi.org/10.1007/s11661-007-9121-x

[38] Y.S. Sato, H. Kokawa, Distribution of tensile property and microstructure in friction stir weld of 6063 aluminum, Metall. Mater. Trans. A 32 (2001) 3023-3031; https://doi.org/10.1007/s11661-001-0177-8

[39] S. Malopheyev, I. Vysotskiy, V. Kulitskiy, S. Mironov, R. Kaibyshev, Optimization of processingmicrostructure-properties relationship in friction-stir welded 6061-T6 aluminum alloy, Mater. Sci. Eng. A 662 (2016) 136-143; https://doi.org/10.1016/j.msea.2016.03.063

[40] M.E. Fitzpatrick, A.T. Fry, P. Holdway, F.A. Kandil, J. Shackleton and L. Suominen: NPL Measurement Good Practice Guide No. 52, 2005

[41] V. Richter-Trummer, E. Suzano, M. Beltrano, A. Roos, J.F. dos Santos, P.M.S.T de Castro, Influence of the FSW clamping force on the final distortion and residual stress field, Mater. Sci. Eng. A 538 (2012) 81-88; https://doi.org/10.1016/j.msea.2012.01.016

[42] ASM Handbook: Fractography, ASM International - Materials Information Society, USA, 1987, vol. 12, p. 857.

[43] ASM Handbook: Fracture and Fatigue, ASM International - Materials Information Society, USA, 1996, vol. 19, p. 2592.

[44] Y. Estrin, A. Vinogradov, Fatigue behavior of light alloys with ultrafine grain structure produced by severe plastic deformation: An overview, Int. J. Fatig. 32 (2010) 898-907; https://doi.org/10.1016/j.ifatigue.2009.06.022

[45] H. Mughrabi, H.W. Hoppel, Cyclic deformation and fatigue properties of very fine-grained metals and alloys, Int. J. Fatig. 32 (2010) 1413-1427; https://doi.org/10.1016/j.ifatigue.2009.10.007

[46] A. Vinogradov, A. Washikita, K. Kitagawa, V.I. Kopylov, Fatigue life of fine-grain Al-Mg-Sc alloys produced by equal-channel angular pressing, Mater. Sci. Eng. A 349 (2003) 318-326; https://doi.org/10.1016/S0921-5093(02)00813-4

[47] S. Rahimi, B.N. Wynne, T.N. Baker, Development of microstructure and crystallographic texture in a double-sided friction stir welded microalloyed steel, Metall. Mater. Trans. A 48 (2017) 362-378; https://doi.org/10.1007/s11661-016-3833-8

[48] S. Rahimi, T.N. Konkova, I. Violatos, and T.N. Baker, Evolution of microstructure and crystallographic texture during dissimilar friction stir welding of duplex stainless steel to low carbonmanganese structural steel, Metall. Mater. Trans. A 50 (2019) 664-687; https://doi.org/10.1007/s11661018-5023-3 


\section{Figure and captions}

Figure 1. Low-magnification optical image of the weld cross section (a), and EBSD orientation maps showing typical grain structures in the base material (b) and the stir zone (c). In (a), AS1 (AS2) and RS1 (RS2) denote advancing and retreating sides of the first and second FSW passes, respectively; dotted line indicates microhardness profile shown in Fig. 3a. In EBSD maps, grains are colored according their crystallographic orientations relative to the WD (color code triangle is shown in the bottom right corner of (b)); LABs and HABs are depicted as white and black lines, respectively.

Figure 2. TEM micrographs showing precipitation patterns in the base material (a), the heat-affected zone (b), and the stir zone (c). Relevant diffraction patterns are shown on the top right corners of the TEM micrographs

Figure 3. Static mechanical properties of the weld: microhardness profile along the dotted line shown in Fig. 1a (a), and the plots of engineering stress-strain curves measured on the base material and a welded specimen with their lengths transverse to the WD (b). In (a), the region between the shoulder diameter and the probe diameter corresponds approximately to the heat-affected zone

Figure 4. Residual stress distributions measured on the weld cross-section (a) along the TD and (b) along the ND. For clarity, the stir zone borderlines are outlined in both maps (dotted lines). AS1 (AS2) and RS1 (RS2) denote advancing and retreating sides of the first and second FSW passes, respectively. Note: the horizontal lines $\mathrm{A}, \mathrm{B}$ and $\mathrm{C}$ show the positions at which the residual-stress profiles were plotted and shown in Fig. 5

Figure 5. Profiles of the residual stress measured along the lines shown in Fig. 4 for (a) TD, and (b) ND

Figure 6. Fatigue lifetime vs applied stress for the base- and welded materials: entire data set (a), the data used for statistical analysis (b). In (a), the arrows represent run-out tests. In (b), solid lines represent median curves whereas dotted lines show 95 pct. confidence bands. See Section 3.3 for details

Figure 7. Typical appearances of the specimens failed during the fatigue tests: base material (a), the weld fatigued at a relatively low stress magnitude and failed in the base material zone (b), and the weld fatigued at a relatively high stress magnitude and failed in the heat-affected zone (c). The magnified images of fracture surfaces are shown in the top right corners of the figures. The dotted lines show the gauge length of each specimen

Figure 8. SEM micrographs showing typical fracture surfaces of the base material: low-magnification overview (a) and characteristic areas given at higher magnifications in (b) through to (d). In (a), the arrow is pointing at the likely crack initiation site. See Section 3.4 for details. Note: The sample fatigued at amplitude stress magnitude of $72 \mathrm{MPa}$

Figure 9. SEM micrographs showing typical fracture surface of the welds, fatigued at a relatively low stress where the failure was occurred at the base-material zone: low-magnification overview (a) and characteristic areas given at higher magnifications in (b) through to (d). In (a), the arrow is pointing at the likely crack initiation site. See Section 3.4 for details. Note: The sample fatigued at amplitude stress magnitude of $76.5 \mathrm{MPa}$

Figure 10. SEM micrographs showing fracture surface of the welds fatigued at a relatively high stress where the failure was occurred at the heat-affected zone: low-magnification overview (a) and characteristic areas given at higher magnifications in (b) through to (d). In (a), the arrow is pointing at the likely crack initiation site. See Section 3.4 for details. Note: The sample fatigued at amplitude stress magnitude of $94.5 \mathrm{MPa}$ 
Figure 11. Typical microstructural patterns observed at the bottom sections of micro-cracks and dimples. See Section 3.4 for details. In (a), the base-material specimen fatigued at amplitude stress magnitude of $85.5 \mathrm{MPa}$ is shown. In (b) the welded specimen fatigued at amplitude stress magnitude of $108 \mathrm{MPa}$ is shown where the failure was occurred at the heat-affected zone

Figure 12. The effect of high-stress fatigue on microhardness profile measured across the welded specimen. See Section 4.3 for details. Note: The experimental data were taken from the weld specimen after fatigue test at amplitude stress magnitude of $108 \mathrm{MPa}$

Supplementary Figure S1. Design of fatigue specimens (units are $\mathrm{mm}$ ). Not in scale. Note: The possible influence of the specimens' position along the weld path was not studied

Supplementary Figure S2. The clamping fixture of the FSW machine used in the present work: top view (a), and side view (b) 

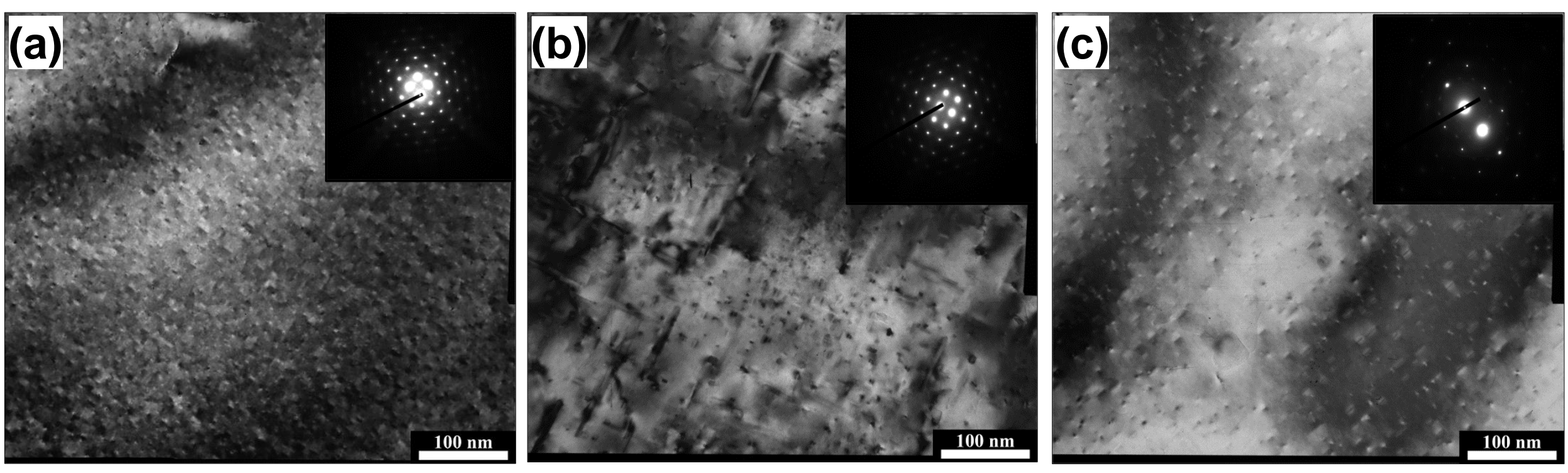

Figure 2. TEM micrographs showing precipitation patterns in base material (a), heat-affected zone (b) and stir zone (c). Appropriate diffraction patterns are shown in the top right corners of the TEM micrographs 


\section{(a)}

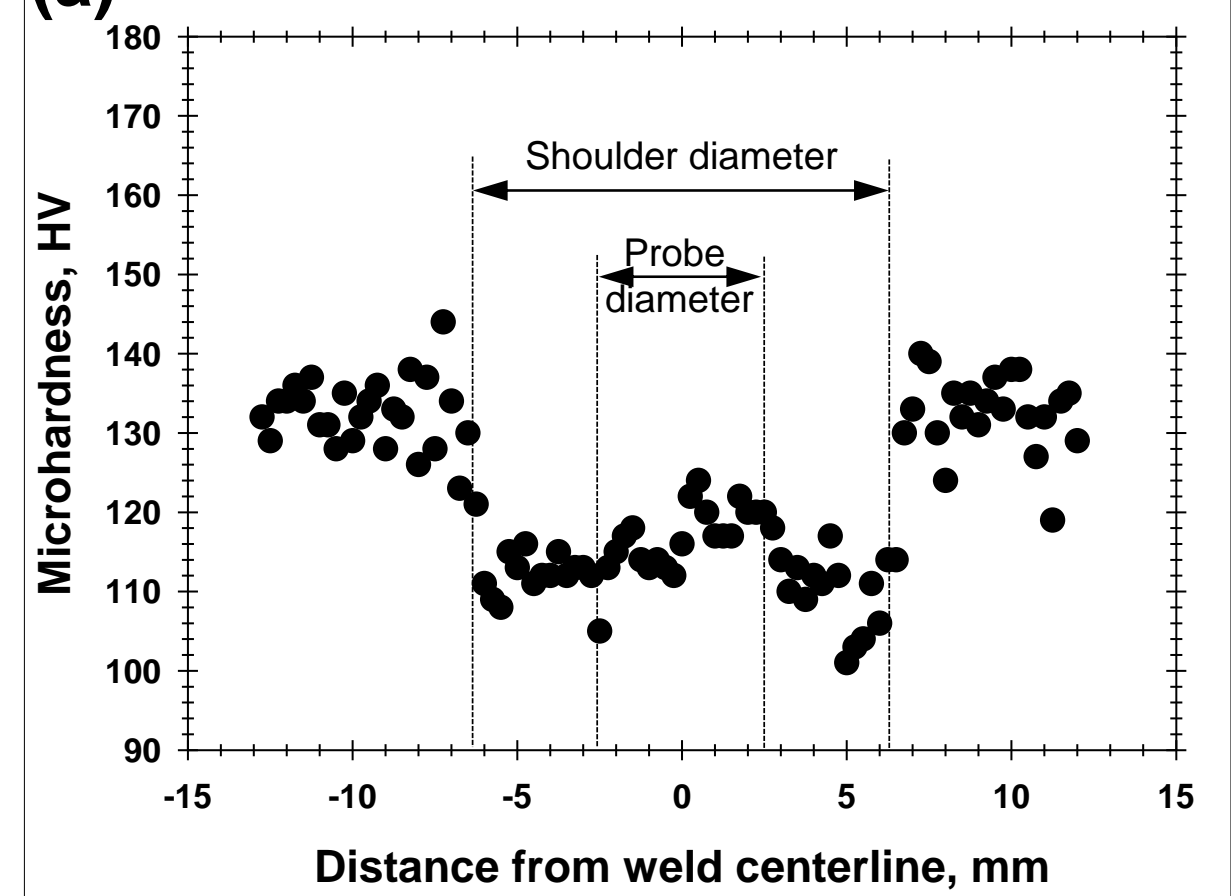

(b)

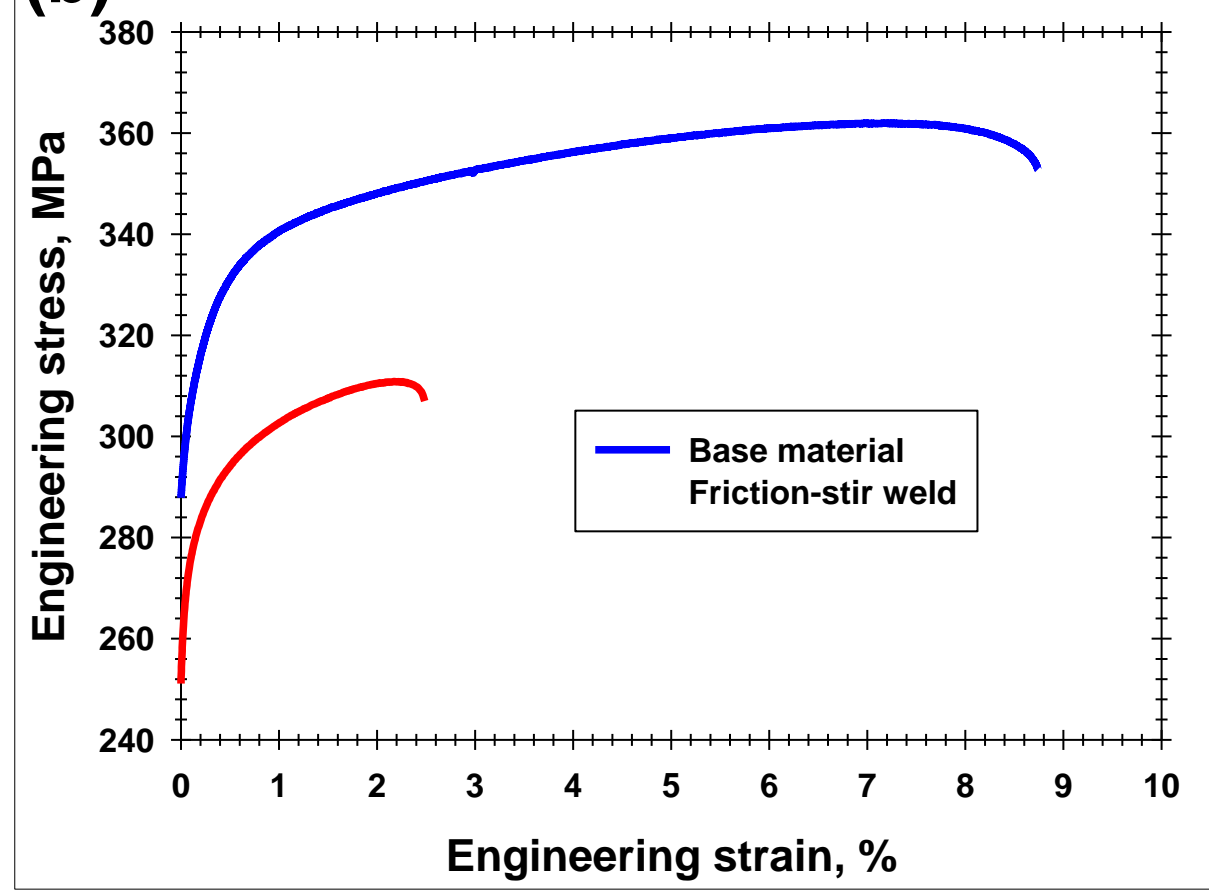

Figure 3. Static mechanical properties of welds: microhardness profile (a) and transverse tensile diagrams (b). In (a), the space between the shoulder diameter and the probe diameter approximately corresponds to heat-affected zone 
(a)
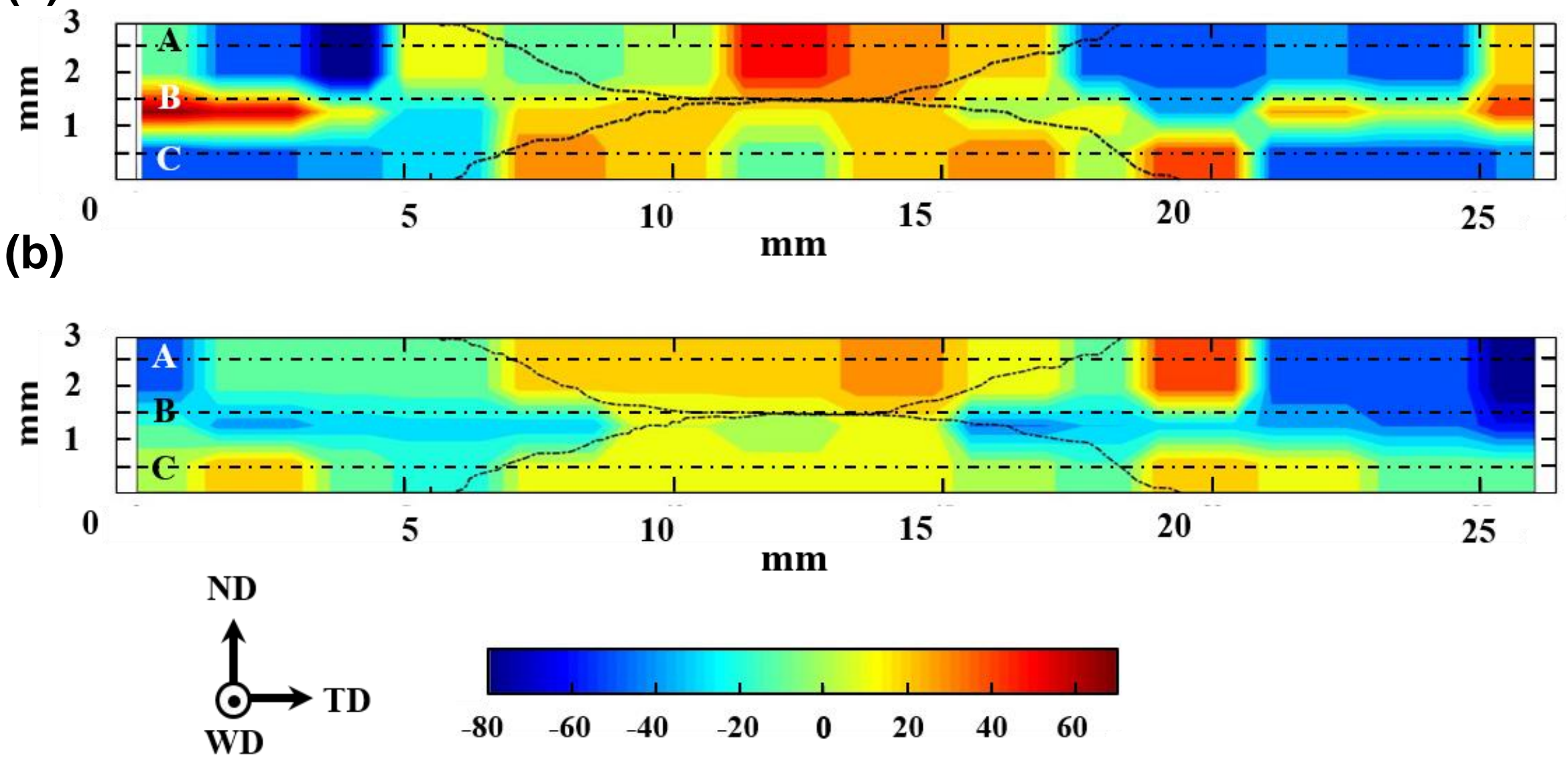

mm

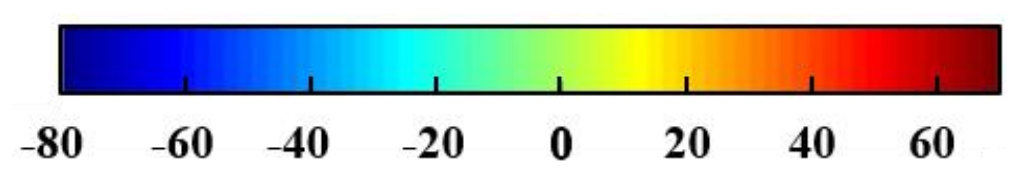

Figure 4. Residual stress distributions measured on the weld cross-section (a) along the TD and (b) along the ND. For clarity, the stir zone borderlines are outlined in both maps (dotted lines). Note: the horizontal lines A, B and $\mathrm{C}$ are the residual-stress profiles shown in Fig. 5. 

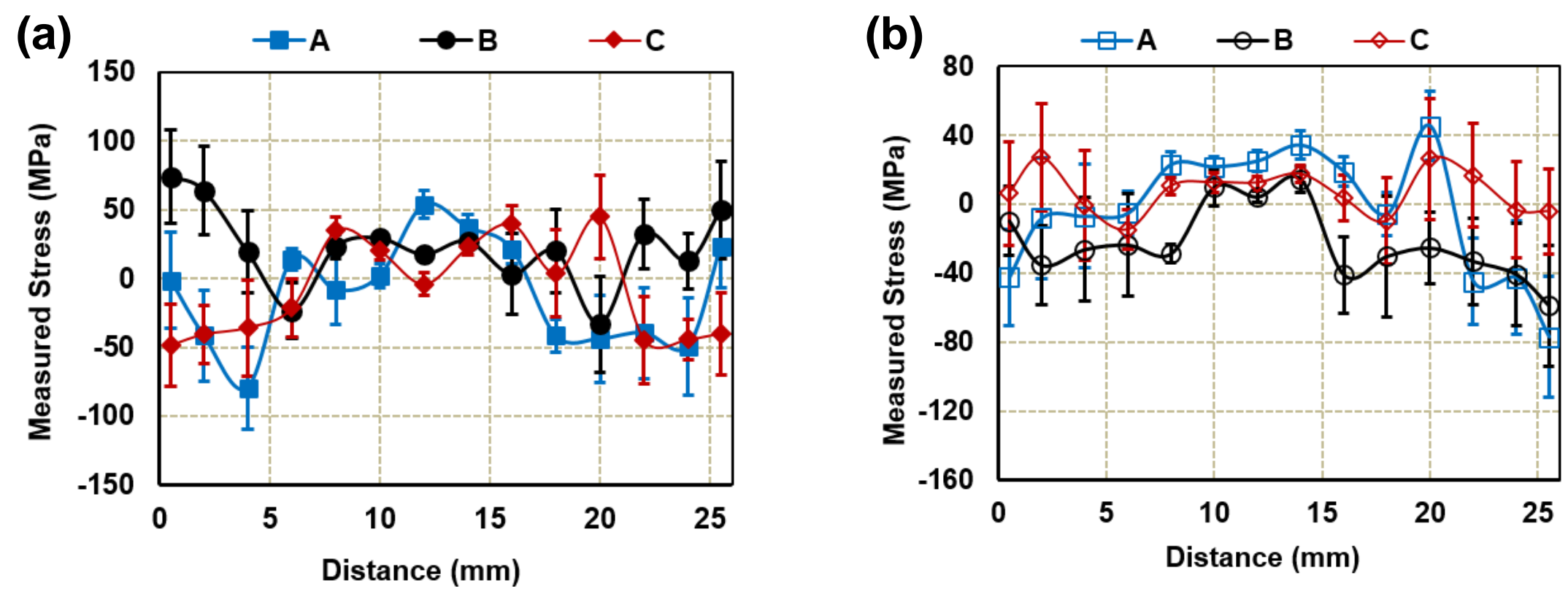

Figure 5. Profiles of the residual stress measured along the lines shown in Fig. 4 for (a) TD, and (b) ND 

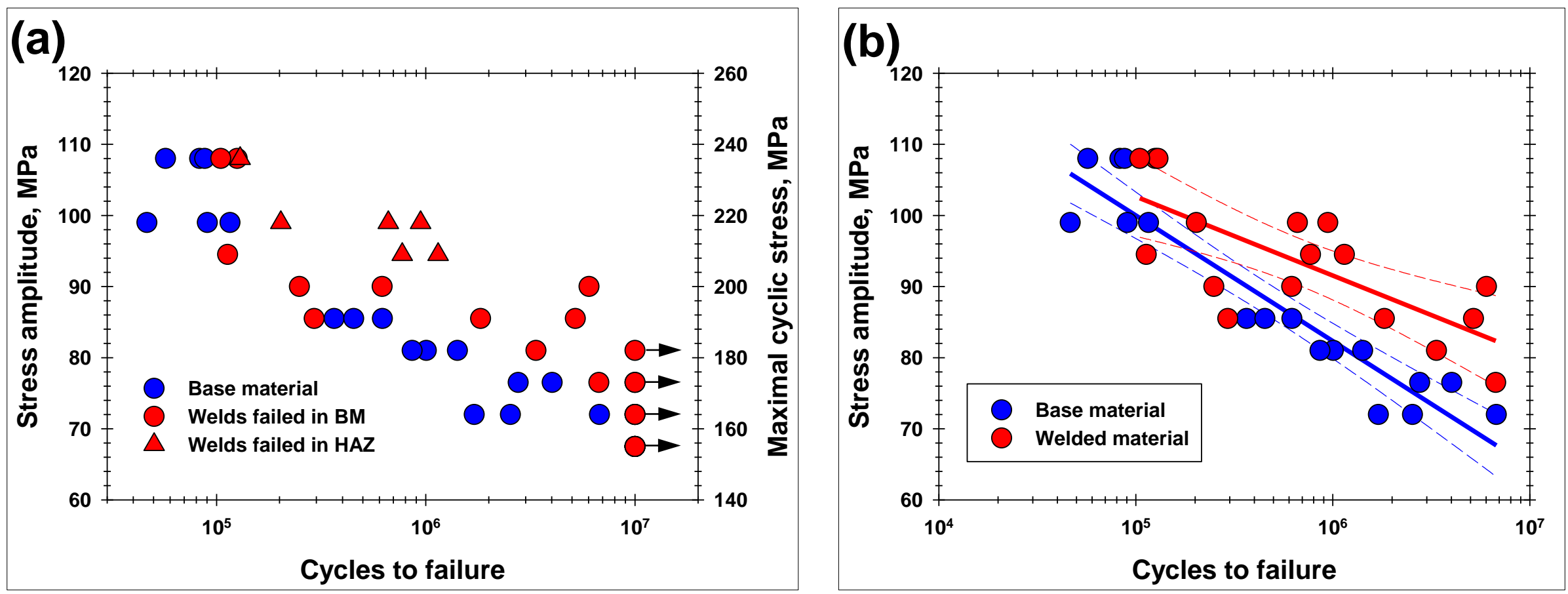

Figure 6. Fatigue lifetime vs applied stress for the base- and welded materials: entire data set (a), the data used for statistical analysis (b). In (a), arrows represent run-out tests; BM and HAZ are base material and heataffected zone, respectively. In (b), solid lines represent median curves whereas dotted lines show 95 pct. confidence bands. See Section 3.3 for details 


\section{(a)}

$20 \mathrm{~mm}$

\section{Amplitude stress of $72 \mathrm{MPa}$}

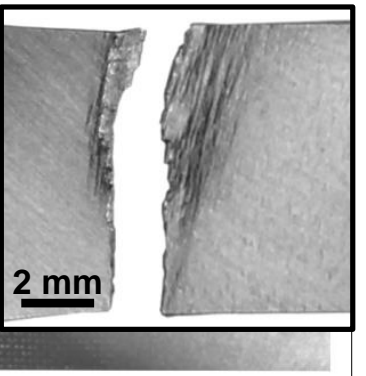

\section{(b)}

$20 \mathrm{~mm}$

\section{Amplitude stress of $90 \mathrm{MPa}$}

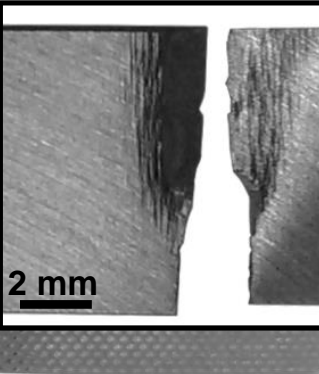

\section{(c)}

$20 \mathrm{~mm}$

\section{Amplitude stress of $99 \mathrm{MPa}$}

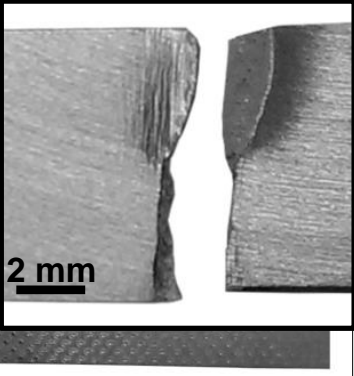

Figure 7. Typical appearance of specimens failed during fatigue tests: base material (a), the weld fatigued at relatively low stress and failed in the base material zone (b), and the weld fatigued at relatively high stress and failed in heat-affected zone (c). The magnified images of fracture surfaces are shown in the top right corners of the figures. The dotted lines show gauge area. See Section 3.4 for details. Note: The amplitude stresses are specified below the specimens. 


\section{(a)}

\section{(b)}

Figure 11. Typical microstructural patterns observed at the bottom sections of micro-cracks and/or dimples. See Section 3.4 for details. In (a), the base-material specimen fatigued at amplitude stress of $85.5 \mathrm{MPa}$ is shown. In (b) the welded specimen fatigued at amplitude stress of $108 \mathrm{MPa}$ and failed in the heat-affected zone is shown 


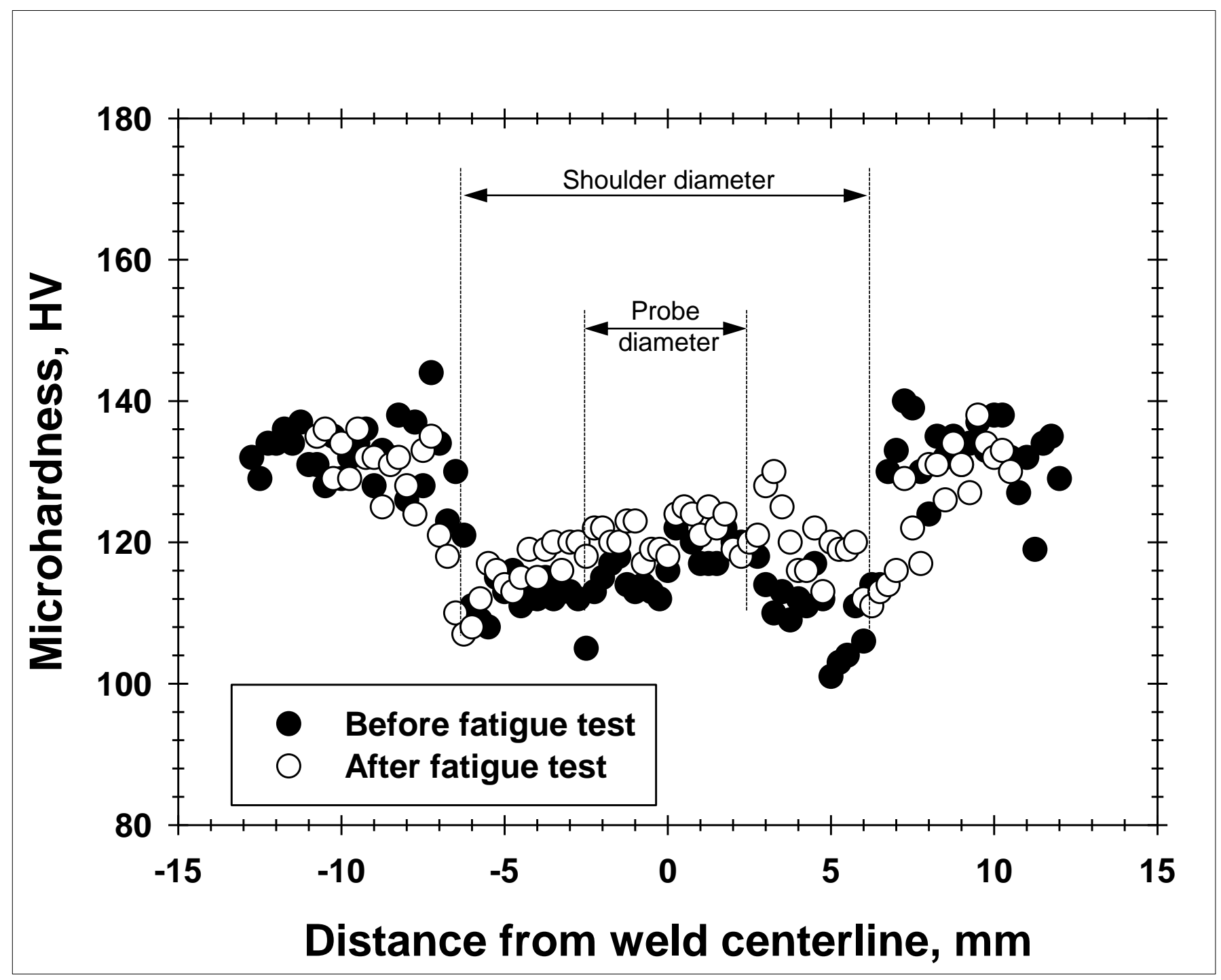

Figure 12. The effect of high-stress fatigue on microhardness profile measured across the welded specimen. See Section 4.3 for details. Note: The experimental data were taken from the weld fatigued at amplitude stress of $108 \mathrm{MPa}$ 
Table 1. Details of the applied stress and number of samples used in the fatigue tests

\begin{tabular}{|c|c|c|c|}
\hline $\begin{array}{c}\text { Amplitude stress, } \\
\mathrm{MPa}\end{array}$ & $\begin{array}{c}\text { Maximal cyclic } \\
\text { stress, MPa }\end{array}$ & \multicolumn{2}{|c|}{ Number of tested specimens } \\
\cline { 3 - 4 } & 150 & Base material & Welded material \\
\hline 67.5 & 160 & 3 & 5 \\
72 & 170 & 2 & 3 \\
76.5 & 180 & 3 & 4 \\
81 & 190 & 3 & 2 \\
85.5 & 200 & - & 3 \\
90 & 210 & - & 3 \\
94.5 & 220 & 3 & 3 \\
99 & 240 & 3 & 3 \\
108 & & 3 & 3 \\
\hline
\end{tabular}

Note: The amplitude stress $\sigma_{a}$ was calculated as $\sigma_{a}=0.5 \times\left(\sigma_{\max }-\sigma_{\min }\right)$, where $\sigma_{\max }$ and $\sigma$ min are maximal- and minimal stress of a loading cycle, respectively.

Table 2. Details of the results of the fatigue tests

\begin{tabular}{|c|c|c|c|c|c|}
\hline \multirow{2}{*}{$\begin{array}{l}\text { Amplitude } \\
\text { stress, MPa }\end{array}$} & \multicolumn{2}{|c|}{$\begin{array}{l}\text { Maximal cyclic stress } \\
\text { (in fraction of yield strength) }\end{array}$} & \multicolumn{2}{|c|}{ Cycles to failure } & \multirow{2}{*}{$\begin{array}{l}\text { Weld failure } \\
\text { location }\end{array}$} \\
\hline & Base material & Welds & Base material & Welds & \\
\hline 67.5 & $0.47 \sigma_{y}$ & $0.55 \sigma_{y}$ & \multicolumn{2}{|c|}{ Run-out tests } & - \\
\hline 72 & $0.50 \sigma_{y}$ & $0.58 \sigma_{y}$ & $\begin{array}{l}1,704,748 \\
2,538,856 \\
6,764,240\end{array}$ & $\begin{array}{l}\text { Three run- } \\
\text { out tests }\end{array}$ & - \\
\hline 76.5 & $0.54 \sigma_{y}$ & $0.62 \sigma_{y}$ & $\begin{array}{l}2,763,392 \\
4,020,179\end{array}$ & $\begin{array}{c}6,717,387 \\
\text { Two run-out } \\
\text { tests }\end{array}$ & $\begin{array}{c}\text { Base material } \\
\text { - }\end{array}$ \\
\hline 81 & $0.57 \sigma_{y}$ & $0.65 \sigma_{y}$ & $\begin{array}{c}861,513 \\
1,006,680 \\
1,417,184\end{array}$ & $\begin{array}{c}3,360,543 \\
\text { One run-out } \\
\text { test }\end{array}$ & $\begin{array}{c}\text { Base material } \\
-\end{array}$ \\
\hline 85.5 & $0.60 \sigma_{y}$ & $0.69 \sigma_{y}$ & $\begin{array}{l}364,845 \\
452,393 \\
620,615\end{array}$ & $\begin{array}{c}292,961 \\
1,829,003 \\
5,183,806\end{array}$ & Base material \\
\hline 90 & - & $0.73 \sigma_{y}$ & - & $\begin{array}{c}248,991 \\
619,010 \\
6,029,954\end{array}$ & Base material \\
\hline 94.5 & - & $0.76 \sigma_{y}$ & - & $\begin{array}{c}112,994 \\
771,268 \\
1,145,951\end{array}$ & $\begin{array}{c}\text { Base material } \\
\text { Heat-affected } \\
\text { zone }\end{array}$ \\
\hline 99 & $0.70 \sigma_{y}$ & $0.80 \sigma_{y}$ & $\begin{array}{r}46,472 \\
90,369 \\
115,993 \\
\end{array}$ & $\begin{array}{l}202,805 \\
661,812 \\
943,967\end{array}$ & $\begin{array}{l}\text { Heat-affected } \\
\text { zone }\end{array}$ \\
\hline 108 & $0.76 \sigma_{y}$ & $0.87 \sigma_{y}$ & $\begin{array}{l}57,046 \\
83,048 \\
87,718\end{array}$ & $\begin{array}{l}125,552 \\
104,777 \\
129,689\end{array}$ & $\begin{array}{c}\text { Base material } \\
\text { Heat-affected } \\
\text { zone }\end{array}$ \\
\hline
\end{tabular}

Note: $\sigma_{y}$ is the yield strength 